\title{
Cryptofaunal diversity in fringing reef rhodoliths
}

\author{
Mira Abrecht $^{1}{ }^{(1)} \cdot$ Viktor Nunes Peinemann $^{1} \cdot$ Ara Kevork Yazaryan $^{1} \cdot$ \\ Madeline Kestler $^{1} \cdot$ Braden Charles DeMattei $^{1} \cdot$ Benjamin A. Hà $^{1}$. \\ Emily Ryznar ${ }^{1}$ - David K. Jacobs ${ }^{1}$
}

Received: 11 April 2021 / Accepted: 7 December 2021/Published online: 20 December 2021

(C) The Author(s) 2021

\begin{abstract}
Rhodolith distribution, morphology, and cryptofauna have been minimally studied on fringing reefs. We present the first study to examine both rhodolith distribution and associated cryptofauna in a tropical fringing reef, located along the microtidal, wave-dominated north shore of Moorea, French Polynesia. We find higher abundances of larger, rounder, and more branching rhodoliths in locations where longer waves impact the fringing reef. Among 1879 animals extracted and identified from 145 rhodoliths, ophiuroids, polychaetes, decapod crustaceans, and gastropods are most abundant, with a wide range of additional taxa contributing to diversity. Large and branching rhodoliths contain the greatest number and diversity of cryptofaunal organisms and are the preferred habitat of rigid-bodied, non-burrowing forms. Overall, exposure to waves entering the lagoon through passes appears to be a critical determinant of rhodolith abundance, morphotype, and in turn cryptofaunal composition in fringing reef habitats.
\end{abstract}

Keywords Cryptofauna - Rhodoliths - CCA - Red algae · Coral reefs $\cdot$ French polynesia

Topic Editor Lauren T.Toth

Mira Abrecht

miabrecht@ucla.edu

$\triangle$ David K. Jacobs

djacobs@ucla.edu

1 Department of Ecology and Evolutionary Biology, University of California, 2162 Terasaki Life Sciences Building, 610 Charles E. Young Drive East, Los Angeles, CA 90095-7239, USA

\section{Introduction}

Rhodoliths are subspherical balls of marine biogenic calcium carbonate whose distribution and internal cryptofaunal biodiversity have received little attention in tropical reef settings. Existing studies note that wave activity influences rhodolith abundance and morphology (Bosselini and Ginsburg 1971; Bosence 1976; Piller and Rasser 1996), and that rhodolith size and complexity positively affect cryptofaunal diversity (Steller et al. 2003; Foster et al. 2013). However, relationships between local environment, rhodolith abundance, and rhodolith morphology have been minimally examined on fringing reefs (but see Weber-van Bosse and Foslie 1904; Pollock 1928; Scoffin et al. 1985). The relationship between rhodolith characteristics and cryptofaunal diversity has also received limited attention in tropical settings (but see Northern Australia: Hutchings and Weate 1977; Hawaii: Brock and Smith 1983; Brazil: Figueiredo et al. 2007). Our study of rhodoliths on the fringing reef tops of Moorea, French Polynesia addresses these limitations.

Rhodoliths form through the accretion of calcifying coralline red algae around coral or rock nuclei subject to intermittent movement by waves, currents, or bioturbation (Marrack 1999; Foster et al. 2013). As rhodoliths rotate, layers of coralline algae accumulate sequentially around the nuclei (Bosence 1983). Rhodoliths typically grow between 0.5 and $1.5 \mathrm{~mm}$ per year, to a reported maximum of $2.7 \mathrm{~mm}$ per year (Frantz et al. 2000; Blake and Maggs 2003; Amado-Filho et al. 2012; Darrenougue et al. 2013). Growth can continue for decades or longer as rhodoliths roll on the benthic substrate (Foster 2002). Variation in rhodolith abundance, morphotype, size, and shape likely relate to environmental factors such as wave energy that influence rotation (Steller and Foster 1995; Piller and 
Rasser 1996), but this relationship remains underexplored, especially on tropical fringing reefs.

Physically complex environments, including coral reefs (Knowlton et al. 2010), harbor communities of cryptofaunal organisms living in hidden or buried microhabitats (Enochs 2012). The internal complexity of rhodoliths similarly supports diverse invertebrate cryptofauna (Nelson 2009), with growth patterns and bioerosion contributing to often intricate interior void spaces (Basso 2009; Nebelsick et al. 2011; Nitsch et al. 2015). Void spaces provide shelter from abrasion and predation (Spieler et al. 2001), attract detritivores by accumulating detritus (Keegan 1974), and support larval settlement (Steller et al. 2003; Steller and Cáceres-Martínez 2009). These voids are typically much larger than sediment pores, yielding more habitable space and thus substantially higher animal biodiversity than adjacent sand habitats (Nelson 2009). As a consequence, researchers have encountered previously undescribed cryptofaunal species in rhodoliths (Clark 2000), emphasizing the importance of studying rhodolith cryptofaunal communities.

Moorea is a wave-dominated reef system with minimal tidal range (Hench et al. 2008). Passes in the barrier reef allow large, long-period ocean waves to enter the lagoon, creating heterogeneity in wave energy along the shallow fringing reef. Significantly, waves are the main driver of rhodolith movement in shallow systems (Marrack 1999). Consequently, Moorea's fringing reef rhodoliths provide a revealing microcosm for the study of interacting physical and biological processes.

Our study assesses rhodolith abundance, morphology, and associated cryptofaunal diversity across the north shore of Moorea to address these important and underexplored topics. We hypothesize that (1) sites with distinctive wave energy regimes exhibit differences in rhodolith abundance, morphotype, volume, and shape; (2) intra-site factors such as water depth, distance from shore, and substrate type that interact with wave energy modulate rhodolith abundance and morphology within a site; and (3) site-related factors and rhodolith abundance in beds, as well as physical characteristics of the rhodoliths themselves, influence the abundance and diversity of associated cryptofauna.

\section{Methods}

To evaluate our hypotheses, we compared wavelengths between sites; measured rhodolith abundance, morphotype, and physical dimensions along transects; and calculated rhodolith volume and shape. Using generalized linear models (GLMs) and multinomial logistic regression (MLR), we tested the relationship of measured parameters to site, location within site, water depth, distance from shore, and substrate type; as well as evaluated the association of morphotype, volume, and shape. Finally, we surveyed cryptofauna present in rhodoliths from different sites; explored these data with principal components analyses (PCA) and multidimensional scaling; and evaluated how cryptofaunal abundance, family diversity, modes of life, and individual taxa vary with location, morphotype, and size. All analyses were conducted in JMP 14.

\section{Selection and description of study sites}

We inspected nine sites along the northern shore of Moorea, selecting three that support rhodoliths. Passes in the barrier reef expose two sites, Talari and Puutara, but not the third, Hilton, to larger waves (Fig. 1a). Snorkel surveys of each site covered a 500 by $100 \mathrm{~m}$ area, informing transect placement for data collection. We characterized substrate and rhodolith presence along each transect. Abridged descriptions of our sites appear below, with detailed descriptions in Online Resource 1.

At Talari Point, northwest of Opunohu Bay (Fig. 1b; $17^{\circ} 29^{\prime} 50^{\prime \prime} \mathrm{S}, 149^{\circ} 51^{\prime} 47^{\prime \prime} \mathrm{W}$ ), a shallow reef flat and nearshore reef crest faces the Tareu Pass in the barrier reef across a $25 \mathrm{~m}$ deep lagoon. Larger ocean waves communicate through the pass, impinging on a fringing reef dominated by crustose algal pavement. Initial surveys noted rhodolith aggregations on sandy substrate in the southeastern portion of the study site, and lower rhodolith densities elsewhere.

East of the Hilton Resort (Fig. 1d, 17 $29^{\prime} 05^{\prime \prime} \mathrm{S}$; $149^{\circ} 50^{\prime} 25^{\prime \prime} \mathrm{W}$ ), the shallow fringing reef has a ragged outer edge that drops to a depth of 3 to $4 \mathrm{~m}$ in the lagoon. The barrier reef protects the fringing reef (Monismith et al. 2014); only smaller trade wind generated waves produced in the lagoon affect the site. Unlike the Talari and Puutara sites, the Hilton site lacks a discrete rhodolith bed.

At Puutara (Fig. 1f, $17^{\circ} 28^{\prime} 51^{\prime \prime}$ S; $149^{\circ} 48^{\prime} 02^{\prime \prime}$ W), a shallow reef flat with a developed crest faces the Irihonu Pass in the barrier reef across a $15 \mathrm{~m}$ deep lagoon. Larger ocean-derived waves from the pass impinge on a fringing reef composed of coralline algae and small corals. Substrate shoreward of the fringing reef crest consists of rubble or sand. The Papeahi River drainage on the western shore of the site creates a cobble substrate. Initial surveys noted rhodolith aggregations shoreward of the fringing reef crest in the northeastern portion of the site.

\section{Wavelength measurements}

The ability to do work, such as moving rhodoliths, reflects wave power, a function of wave height and wave period. These parameters strongly correlate with wavelength (e.g., Sverdrup et al. 1942). Wavelength measurement via 


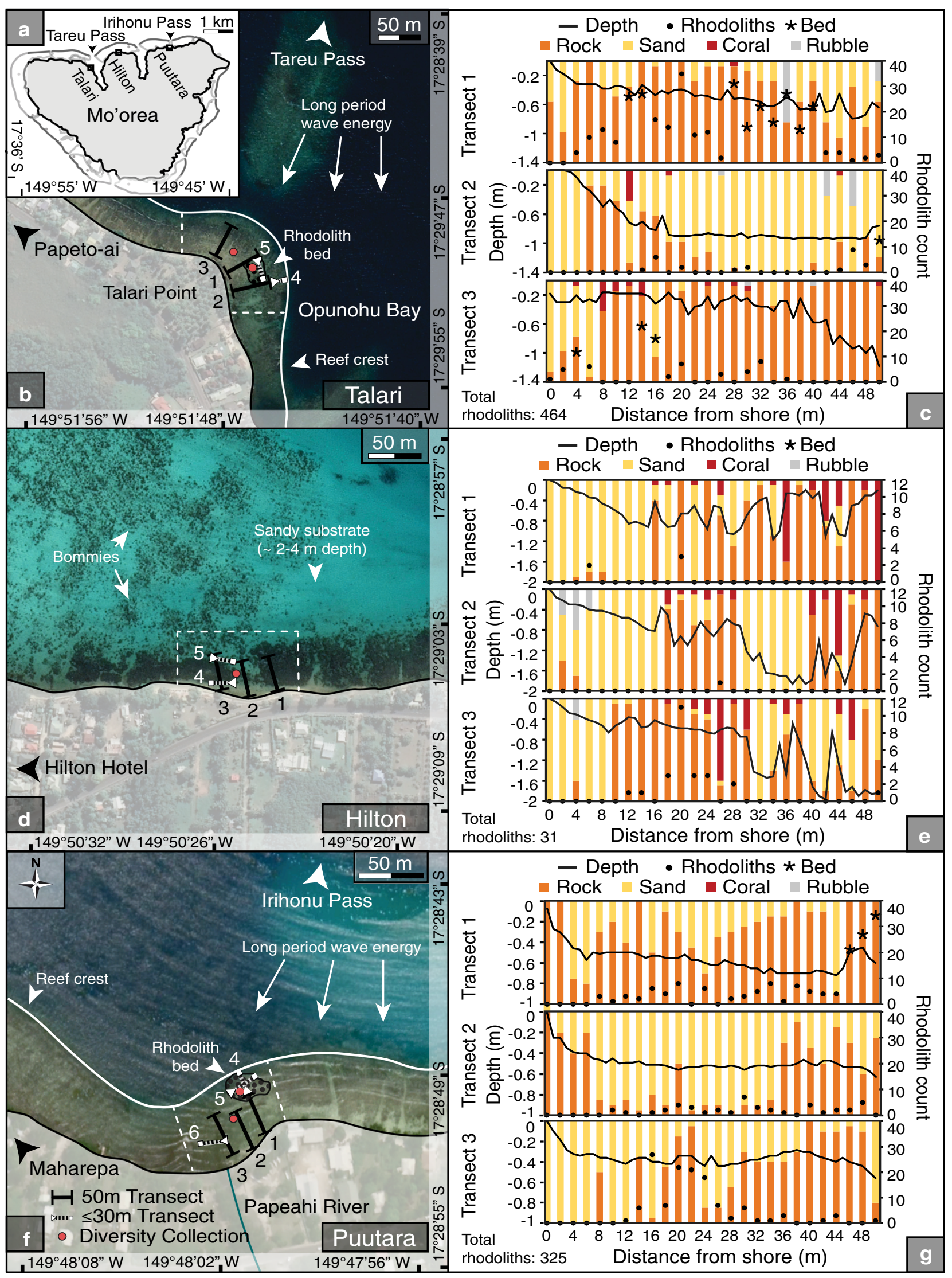


4Fig. 1 Map of study sites and initial transects. a Map of Moorea with study sites marked as squares. b, d, f Expanded images of the Talari, Hilton, and Puutara study sites, respectively. Numbered solid black lines represent initial $50 \mathrm{~m}$ transects, while dashed lines represent additional transects less than $30 \mathrm{~m}$ long. Red dots mark cryptofauna collection points. c, e, g Benthic topology and rhodolith community along initial transects at the Talari, Hilton, and Puutara sites, respectively. Black lines represent water depth in meters. Black dots represent rhodolith count in each $0.25 \mathrm{~m}^{2}$ quadrat. Substrate composition is represented through color. Asterisks mark the positions of rhodolith beds based on total volume calculations. Site images are modified from Google Earth

Google Earth images proved the best available proxy for comparing wave energy given the limited spatial scale and thus wave size of the lagoon sites. This allowed simple comparison of contemporaneous wave activity between sites. Dates where waves were visible due to low angles of incident light were chosen for analysis. These included 5 dates for the Talari site and 4 dates each for the Hilton and Puutara sites. Wavelength on each date for each site was measured by averaging the distance between five waves approaching the fringing-reef crest. We calculated wave base by halving wavelength. Wave base was less than lagoon depth, confirming that open water wave models were relevant (see Sverdrup et al. 1942). We determined whether the Talari and Puutara sites had higher wavelengths than the Hilton site via paired, one-tailed t-tests of wavelengths measured at the same date.

\section{Rhodolith distribution and characteristics}

\section{Survey of rhodolith distribution and characteristics}

Transects captured variation in benthic habitat and transitions in rhodolith distribution. Three $50 \mathrm{~m}$ transects at each site, oriented perpendicular to shore, provided a standard set of measurements (Fig. 1b, d, f). Additional, shorter transects extended standard transects to reach the reef edge at the Talari and Puutara sites, while $30 \mathrm{~m}$ shore-parallel transects explored salient features at each site (Online Resource 2 Fig. 1a, c, e ).

For all transects, water depth was measured every meter; percent coverage of four substrate types-smooth carbonate rock, loose sand, live coral, and pebbles or larger coral rubble-were estimated every $2 \mathrm{~m}$ using a $0.25 \mathrm{~m}^{2}$ quadrat; and the abundance, morphotype, and dimensions of rhodoliths along each transect were assessed every $2 \mathrm{~m}$ within a separate $0.25 \mathrm{~m}^{2}$ quadrat. For transects perpendicular to shore, we placed quadrats every $2 \mathrm{~m}$. For transects parallel to shore, we placed quadrats every meter to capture transitions in rhodolith distribution, and every 2-3 $\mathrm{m}$ where no such transitions occurred. We defined rhodoliths as rubble having $\geq 50 \%$ coverage of crustose coralline algae. We first identified the type of substrate-smooth carbonate rock, loose sand, live coral, fine pebbles, or coral rubbleunderneath each rhodolith, then categorized each rhodolith into one of three morphotypes defined by Bosence (1983): laminar, columnar, or branching (Fig. 2). Following Sneed and Folk (1958), we measured three orthogonal axes for each rhodolith: the long (L), intermediate (I), and short (S) diameters.

\section{Calculation of volume, shape, and rhodolith bed}

Using the three orthogonal axes, we calculated rhodolith volume (Teichert 2014) and categorized each rhodolith into one of three shape classes: discoidal, ellipsoidal, or spheroidal (Sneed and Folk 1958). Rhodoliths between shape classes were classified as mixed. Following Graham and Midgley (2000), we generated ternary diagrams of shape from the three axes. We defined quadrats with over $5000 \mathrm{~cm}^{3}$ total rhodolith volume as rhodolith beds. This excluded the numerous but small coated grains within the Papeahi River drainage channel, a separate phenomenon beyond the scope of our study.

\section{Statistical analysis of rhodolith distribution and characteristics}

Using GLMs and MLR, we evaluated whether location (site, transect) and benthic characteristics (distance from shore, water depth, substrate) influence rhodolith abundance. Different series of GLMs used site and transect as location predictors, as disparities in degrees of freedom precluded combined site-transect models. Initial tests crossed distance from shore, water depth, and location (Online Resource 2 Table 1). Shore-parallel transects lacked distance from shore measurements and were thus excluded from tests of distance. Predictors that were not significant based on false discovery rate (FDR) logworth values and did not compose significant predictor crosses were sequentially eliminated to generate models for each analysis. Predictors from resultant models were crossed with percent substrate cover, where four substrate types functioned as separate predictors (Online Resource 2 Table 2). All models employed a Poisson distribution and $\log$ link function.

We also tested predictions that location and benthic characteristics control rhodolith morphotype, volume, and shape. Categorical variables (morphotype and shape) were investigated using MLR models, while continuous variables (volume) were investigated using GLMs. As before, site and transect were tested in parallel. We crossed distance from shore, water depth, and location to predict morphotype, volume, and shape, eliminating factors that 


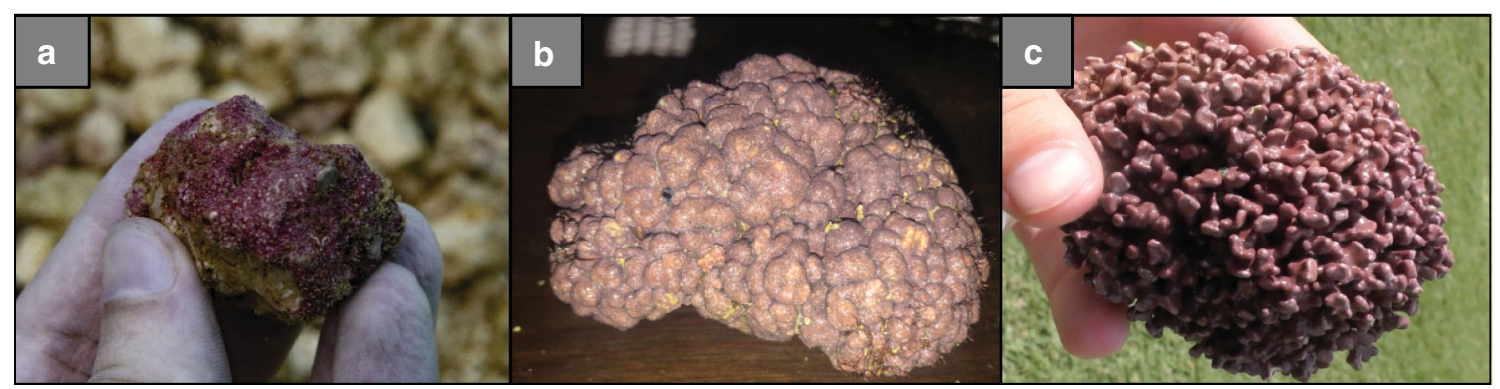

Fig. 2 Three rhodolith morphotypes examined in study. a Laminar: algal coating lacks major protrusions. b Columnar: bumpy surface has rounded protuberances and few internal cavities. c Branching: tightly packed protrusions produce complex internal void spaces

were not significant based on FDR logworth values (Online Resource 2 Table 1). We then crossed these models with the underlying substrate type (Online Resource 2 Table 2). We excluded the "mixed" category from models predicting shape, as it did not differentiate between discoidal/spheroidal, ellipsoidal/spheroidal, or ellipsoidal/ discoidal intermediates. In GLM models predicting volume, we log-transformed volume to employ a normal distribution and identity link function.

To assess relationships between rhodolith morphotype, volume, and shape, we generated a GLM crossing rhodolith morphotype and shape to predict rhodolith volume, and used MLR to compare rhodolith morphotype and shape. GLMs employed a normal distribution, identity link function, and $\log$ transformation.

\section{Cryptofauna abundance and diversity}

\section{Collection of rhodoliths and extraction of cryptofauna}

To survey cryptofaunal communities in rhodoliths from different locations, we selected five collection points across the three study sites. We chose two points-one inside a rhodolith bed, and one outside - at both the Talari and Puutara sites to evaluate effects of beds on cryptofauna, and one collection point at the Hilton site, which lacked a bed. We collected 10 rhodoliths of each morphotype using an expanding spiral search pattern around each collection point. Because the Hilton site had few branching rhodoliths, only three were collected from this site. To ensure comparable rhodolith volume between sites and morphotypes, collections were restricted to rhodoliths with a long diameter between 6 and $10 \mathrm{~cm}$. Individually labelled rhodoliths isolated in closed bags were maintained in flowthrough seawater until dissection.

To recover endofauna, we broke rhodoliths into approximately $1 \mathrm{~cm}^{3}$ fragments using hammers and chisels, removed macroscopic cryptofauna using forceps, and extracted hidden organisms by submerging rhodolith fragments in fresh water. Organisms that emerged from rhodoliths while in collection bags were also recorded. Specimens were identified to the lowest possible taxonomic level using resources for specific groups, including Salvat and Rives (1991) for molluscs and Fauchald (1977) for polychaetes. We confirmed these identifications with imagery from the UC Berkeley Moorea BIOCODE project (Meyer 2017) and used the WoRMS (WoRMS Editorial Board 2020) system of classification to standardize species taxonomy. Most cryptofaunal organisms were identified to the genus and species levels, and nearly all were identified to the family level. However, we excluded sponges from analysis and classified immature cnidarians only to phylum due to challenges in visual identification.

In addition to taxonomy, we categorized organisms by body form and motility at the order level, as these traits appeared to respond similarly to rhodolith morphology across taxa. Categories of body form included rigid (hardshelled or spinose), articulated (hard-bodied but bendable), and flexible (soft-bodied). Categories of motility included active non-burrower, motile burrower, and sessile infauna.

\section{Statistical analysis of cryptofauna abundance and diversity}

The number of organisms and families in each rhodolith were used as measures of abundance and diversity, respectively. Five potential predictors-site, association with rhodolith bed, rhodolith morphotype, volume, and shape-were screened in JMP. The FDR logworth of site, bed association, and shape failed to reach threshold significance for both abundance and diversity, eliminating these predictors from this analysis.

To further assess the relationship between these factors, we performed PCA using order-rank taxa with more than 10 observations as variables. Dummy variables, displayed on the PCA but not included in analyzed data, included rhodolith morphotype, association with rhodolith bed, and volume, as well as organism abundance, diversity, and categories of body shape and motility. Multidimensional scaling was performed with the same taxa to better evaluate 
the role of the most abundant groups in shaping relationships between different factors.

To further test relationships between rhodolith characteristics and cryptofauna, we input morphotype and volume as predictors in two fully-crossed GLMs predicting abundance and diversity. Each GLM employed a Poisson distribution and log link function. GLMs assessed predictors of abundance for each phylum, as well as for each order exceeding 10 individuals. We additionally analyzed categories of body form and motility, as well as the four most abundant decapod families, which were not well explored in the order-level analysis. Each fully-crossed GLM used rhodolith morphotype, volume, and association with rhodolith bed as predictors, and employed a Poisson distribution and log link function. We eliminated non-significant predictors in order of descending p-value. Additional GLMs using site as predictor were performed on sipunculan orders.

\section{Results}

\section{Rhodolith distribution and characteristics}

Sites adjacent to barrier reef passes are exposed to longer wavelengths and thus higher wave power than protected sites. As a result, waves at the Talari (paired t-test: $\mathrm{t}=-$ 5.28, $p=0.007$ ) and Puutara (paired t-test: $\mathrm{t}=3.16, p=$ $0.04)$ are significantly longer than those at the Hilton site (Table 1).

The wave-exposed Talari and Puutara sites contain more rhodoliths (GLM: $\mathrm{X}^{2}=43.51, p<0.0001$ ), more branching morphotypes (MLR: $\mathrm{X}^{2}=10.42, p=0.03$ ), larger rhodoliths (GLM: $\left.X^{2}=208.60, p<0.0001\right)$, and rounder rhodoliths (MLR: $\mathrm{X}^{2}=65.04, p<0.0001$ ) compared to the Hilton site (Fig. 3). At these sites, slightly deeper outer portions of the fringing reef face the wave source from the pass and experience breaking waves. Thus, increased depth and distance from shore relate to greater wave energy, and more wave-exposed locations at the Talari and Puutara sites support larger (GLM: $\mathrm{X}^{2}=10.31, p=0.001$ for distance; $X^{2}=12.05, p=0.0005$ for depth) and more branching (MLR: $\mathrm{X}^{2}=12.41, p=0.01$ for site-distance cross; $\mathrm{X}^{2}=31.76, p<0.0001$ for site-depth cross) rhodoliths (Fig. 1c, e, g; Online Resource 2 Fig. 1b, d, f). Carbonate rock substrate appears associated with high wave energy, and more (GLM: $\mathrm{X}^{2}=13.10, \mathrm{p}=0.0003$ ) large (GLM: $\mathrm{X}^{2}=17.45, p=0.0006$ ), branching (MLR: $\mathrm{X}^{2}=45.69, \mathrm{p}<0.0001$ for transect-substrate cross) rhodoliths appear on rock substrate (Online Resource 2 Table 2). Additional tests support relationships between morphotype and shape (MLR: $\mathrm{X}^{2}=82.62, p<0.0001$ ) and morphotype and volume (GLM: $X^{2}=113.36$, $p<0.0001$ ) (Online Resource 2 Table 3): branching rhodoliths are largest and most spheroidal, while laminar rhodoliths are smallest and most ellipsoidal.

\section{Cryptofaunal abundance and diversity}

From 1879 organisms recovered from 145 rhodoliths, we identified 177 distinct taxa across 9 phyla, 19 classes, 38 orders, and 86 families. We identified $98 \%$ of individual organisms to the family level or below. Arthropods ( $n=621)$, annelids $(n=556)$, echinoderms $(n=494)$, and molluscs $(n=134)$ were most common.

In our PCA, the first 2 axes have eigenvalues over 2 , and explain $24 \%$ and $13 \%$ of variation, respectively (Fig. 4). Axes 3-8 yield similar loadings (eigenvalues between 1.7

Table 1 Wavelength and wave base across study sites

\begin{tabular}{|c|c|c|c|c|c|c|c|c|}
\hline \multirow[t]{2}{*}{ Measurement } & \multicolumn{5}{|l|}{ Year } & \multirow[t]{2}{*}{ Average } & \multicolumn{2}{|l|}{ Site comparison } \\
\hline & Feb 2013 & Feb 2016 & May 2017 & Feb 2018 & Aug 2019 & & Talari-Hilton & Puutara-Hilton \\
\hline \multicolumn{9}{|c|}{ Wavelength (m) } \\
\hline Talari & 12.17 & 11.83 & 6.09 & 12.50 & 9.00 & $10 \pm 1$ & $t=-5.28 p=0.007$ & $t=3.16 p=0.04$ \\
\hline Hilton & 2.89 & 2.65 & 2.79 & 4.18 & - & $3.3 \pm 0.4$ & & \\
\hline Puutara & 12.38 & 10.47 & 5.33 & - & 6.95 & $9 \pm 2$ & & \\
\hline \multicolumn{9}{|l|}{ Wave base (m) } \\
\hline Talari & 6.9 & 5.92 & 3.05 & 6.25 & 4.50 & $5.2 \pm 0.6$ & & \\
\hline Hilton & 1.45 & 1.33 & 1.40 & 2.09 & - & $1.6 \pm 0.2$ & & \\
\hline Puutara & 6.19 & 5.24 & 2.67 & - & 3.48 & $4.4 \pm 0.8$ & & \\
\hline
\end{tabular}

Wavelength was measured from Google Earth images at each site, while wave base was calculated as half the measured wavelength. Months and years represent the same image dates. Variance is reported as standard error. Dashes (-) mark wavelengths that were unable to be measured. Italic text marks significant results showing that the Talari and Puutara sites experience longer wavelengths, and thus higher wave energy, than the Hilton site 
Fig. 3 Variability in rhodolith morphotype, size, and shape across study sites. Colors mark transects in each panel. a Rhodolith abundance plotted by morphotype, distinguished by pattern, for each transect. b Average rhodolith volume plotted by morphotype for each transect. Error bars represent standard error. c Ternary diagrams plotting the shape of rhodoliths found at the Talari, Hilton, and Puutara sites. Larger dots represent the average rhodolith shape in each transect

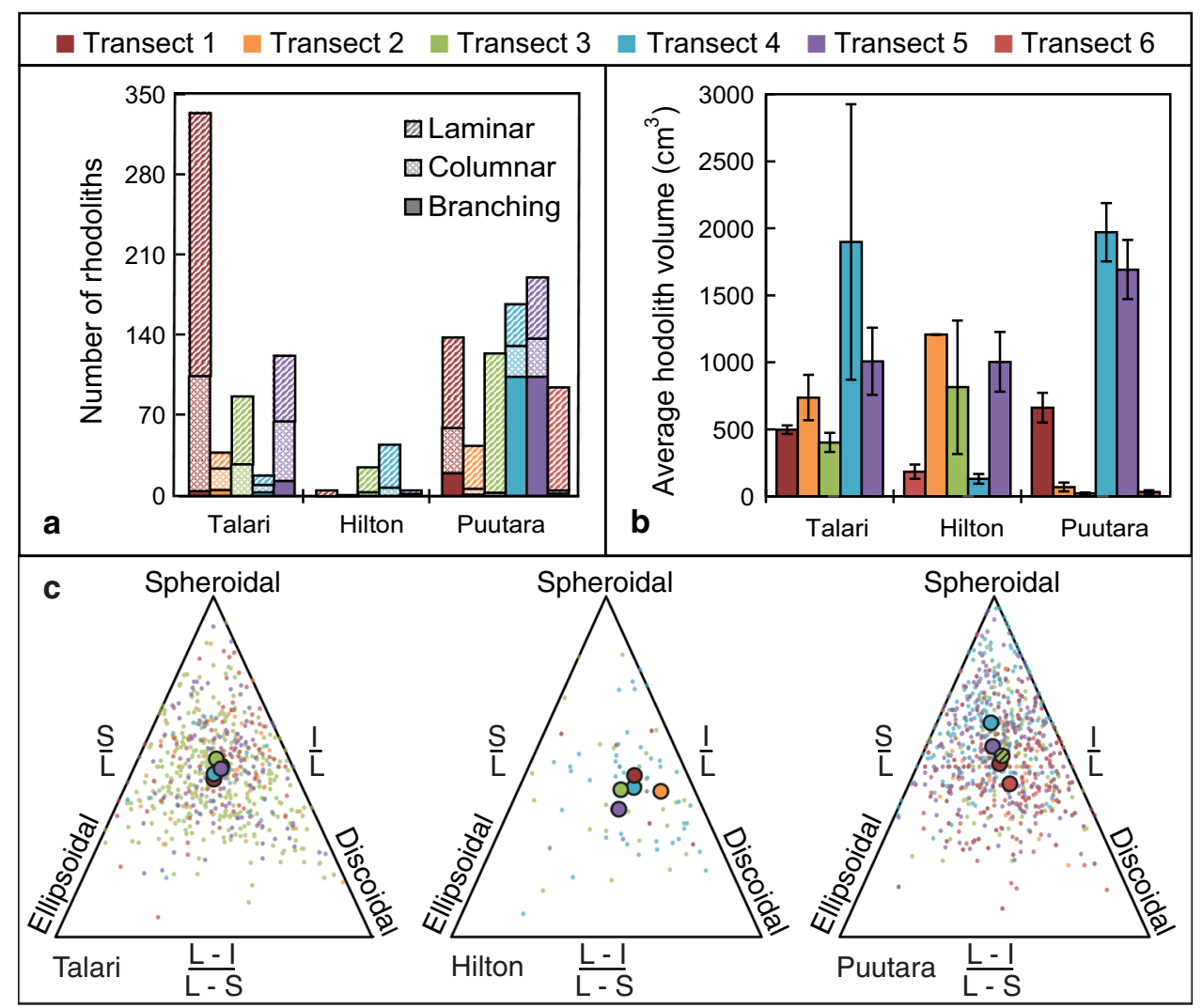

and 1) and are not considered further. Dummy variables rhodolith size and branching morphotype, as well as organism abundance and number of families, correlate with Axis 1. Multidimensional scaling places greater emphasis on the most abundant taxa, with ophiuroid orders and decapod crustaceans loading high on a comparable Axis 1 (Online Resource 3 Fig. 1), likely reflecting the wavedominated settings with large, branching rhodoliths also noted in the PCA. PCA Axis 2 separates burrowing, softbodied organisms from more active and hard-bodied organisms-possibly representing a distinction between fauna within and on top of or underneath rhodoliths. In multidimensional scaling, eunicids, the most abundant softbodied burrowing annelids, show strong Axis 2 loading. This axis also associates with distinctions between columnar and laminar rhodoliths, and between isolated rhodoliths and those in rhodolith beds. GLMs below test the significance of patterns suggested by these ordinations.

\section{Tests of cryptofaunal abundance and diversity}

Branching rhodoliths support significantly more individuals (GLM: $X^{2}=47.33, p<0.0001$ ) and families (GLM: $\left.\mathrm{X}^{2}=45.85, p<0.0001\right)$ than columnar and laminar morphotypes (Fig. 5a, b). Regardless of morphotype, larger rhodoliths contain more organisms (GLM: $\mathrm{X}^{2}=12.54$, $p=0.0004$ ) (Fig. 5c) and families (GLM: $\mathrm{X}^{2}=0.0002$, $p=0.0002$ ) (Fig. 4d) (Online Resource 3 Table 1).

\section{Tests of cryptofaunal body shape and motility}

Active, non-burrowing (GLM: $\mathrm{X}^{2}=42.72, p<0.0001$ ), rigid (GLM: $X^{2}=41.26, p<0.0001$ ), and articulated forms (GLM: $\mathrm{X}^{2}=26.66, p<0.0001$ ) strongly associate with large and branching rhodoliths, consistent with their need for open space. Both motile and sessile burrowers, as well as soft-bodied, flexible organisms, exhibit no relationship with morphotype or size, consistent with their reduced need for open space (Online Resource 3 Table 2).

\section{Tests of individual taxa}

Echinoderms associate with large (GLM: $X^{2}=11.49$, $p=0.0007)$ and branching rhodoliths (GLM: $\mathrm{X}^{2}=71.42$, $p<0.0001$ ) (Fig. 6a) driven by the active, articulated brittle star orders Ophiacanthida (GLM: $\mathrm{X}^{2}=12.98$, $\mathrm{p}<0.0001$ for volume; $\mathrm{X}^{2}=58.67, p=0.0003$ for morphotype) and Amphilepidida (GLM: $\quad X^{2}=48.09$, $p<0.0001$ for morphotype) (Fig. 6b) (Online Resource 3 Table 3).

Arthropods associate with large (GLM: $X^{2}=18.35$, $p<0.0001$ ), branching (GLM: $\mathrm{X}^{2}=42.13, p<0.0001$ ) 


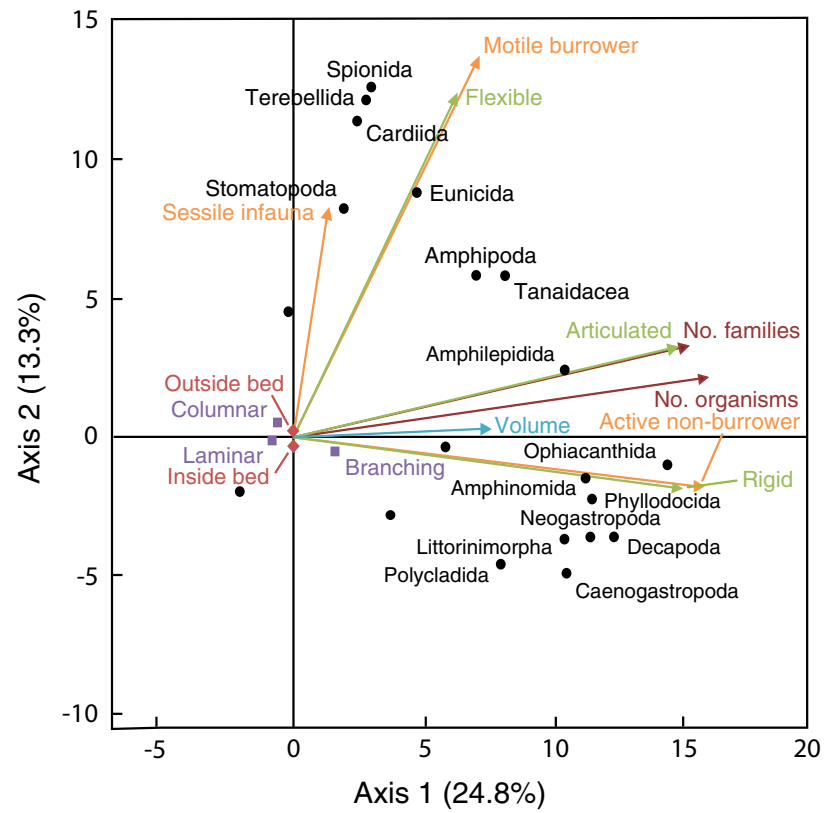

Fig. 4 PCA of rhodolith cryptofauna conducted on 145 rhodoliths with 20 orders of cryptofauna as variables. Orders are represented by black dots. Loadings for dummy variables are plotted as colored arrows, and include rhodolith volume (blue), as well as number of organisms and families per rhodolith (burgundy). Numerical dummy variables derived from grouping taxa by common properties are also plotted with colored arrows, and include body flexibility (green) (includes rigid or spiny forms, articulated or elongate forms, and flexible forms) and mode of life (orange) (includes active nonburrowers, motile burrowers, and sessile infauna). Categorical dummy variables derived from rhodoliths rather than fauna are plotted with colored dots, and include position in or out of rhodolith bed (red) and rhodolith morphotype (purple) (includes branching, columnar, laminar). These variables scale differently to orders and numerical dummy variables, and thus plot nearer to the axial intersection, but still show the relative position of rhodoliths with different characteristics on the PCA. Note that volume, number of organisms, number of families, and branching morphology, as well as taxa and taxa properties associated with branching open forms, are associated with Axis 1, while flexible and burrowing forms less dependent on open space load higher on Axis 2

rhodoliths (Fig. 6a), driven primarily by active, hardshelled decapods (GLM: $X^{2}=26.46, \mathrm{p}<0.0001$ for volume; $X^{2}=89.31, p<0.0001$ for morphotype) (Fig. 6c). Within Decapoda, rigid, active xanthids (GLM: $\mathrm{X}^{2}=81.35, p<0.0001$ ), alpheids (GLM: $\mathrm{X}^{2}=48.69$, $p<0.0001$ ), and pagurids (GLM: $\mathrm{X}^{2}=20.16, p<0.0001$ ) associate with branching rhodoliths. Articulated amphipods as well as burrowing tanaids and stomatopods show little relationship with branching rhodoliths (Online Resource 3 Table 3).

Polychaetes associate with large rhodoliths (GLM: $\left.\mathrm{X}^{2}=13.75, p=0.0002\right)$ driven by boring, soft-bodied eunicids (GLM: $\mathrm{X}^{2}=4.72, p=0.03$ ). Non-boring, articulated amphinomids (GLM: $\mathrm{X}^{2}=34.78, p<0.0001$ ) and phyllodocids (GLM: $\mathrm{X}^{2}=43.33, p<0.0001$ ) associate
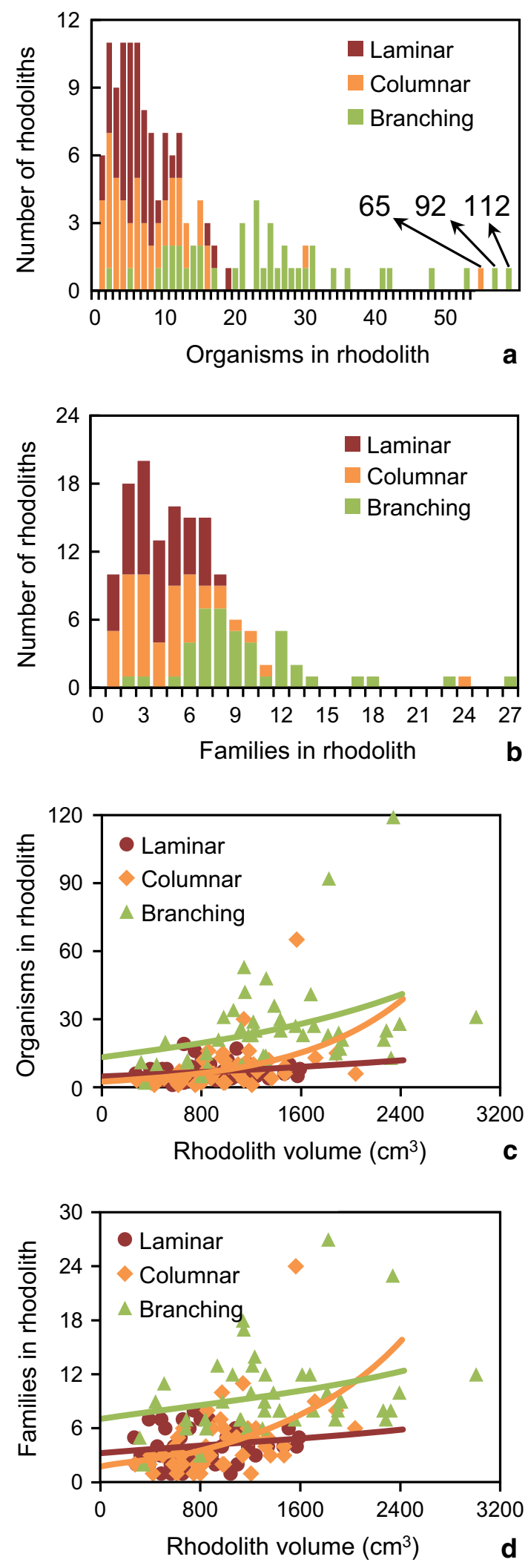
4 Fig. 5 Number of organisms found in different rhodolith morphotypes at all sites. Colors represent rhodolith morphotypes in each panel. a Histogram of organismal abundance in rhodoliths, arranged by morphotype. b Histogram of number of families in rhodoliths, arranged by morphotype. c Organismal abundance by rhodolith volume, analyzed by morphotype. d Familial diversity by rhodolith volume, analyzed by morphotype. Fit lines follow relationships between abundance or diversity and rhodolith volume calculated via GLMs for each morphotype. p-values for these lines are listed here. Panel c branching, $p=0.005$; columnar, $p=0.0005$; laminar, $p=0.11$. Panel d branching, $p=0.05$; columnar, $p<0.0001$; laminar: $p=0.31$

with branching rhodoliths (Fig. 6d). Notably, sedentary, soft-bodied polychaete groups such as terebellids (GLM:
$\left.\mathrm{X}^{2}=16.76, p<0.0001\right)$, capitellids (GLM: $\mathrm{X}^{2}=21.64$, $p<0.0001$ ), and spionids (GLM: $\mathrm{X}^{2}=20.26, p<0.0001$ ) associate with isolated rhodoliths (Online Resource 3 Table 3).

Molluscs associate with large rhodoliths (GLM: $\left.\mathrm{X}^{2}=14.03, \quad p=0.0002\right)$, driven by Caenogastropoda (GLM: $X^{2}=7.62, \quad p=0.006$ ), Neogastropoda (GLM: $\mathrm{X}^{2}=8.58, p=0.003$ ), and Trochida (GLM: $\mathrm{X}^{2}=8.99$, $p=0.003)$. Overall, molluscs don't respond to rhodolith morphotype (Fig. 6e) (Online Resource 3 Table 3).

Sipunculans associate with isolated rhodoliths (GLM: $\mathrm{X}^{2}=10.30, p=0.001$ ), driven by Golfingiida (GLM: $\mathrm{X}^{2}=12.36, p=0.001$ ) (Online Resource 3 Table 3 ).
Fig. 6 Differential distribution of invertebrate phyla in rhodolith morphotypes. a Average abundances of each phylum across three rhodolith morphotypes. b-d ch panel and are presented in order of abundance in branching rhodoliths. Error bars represent standard error
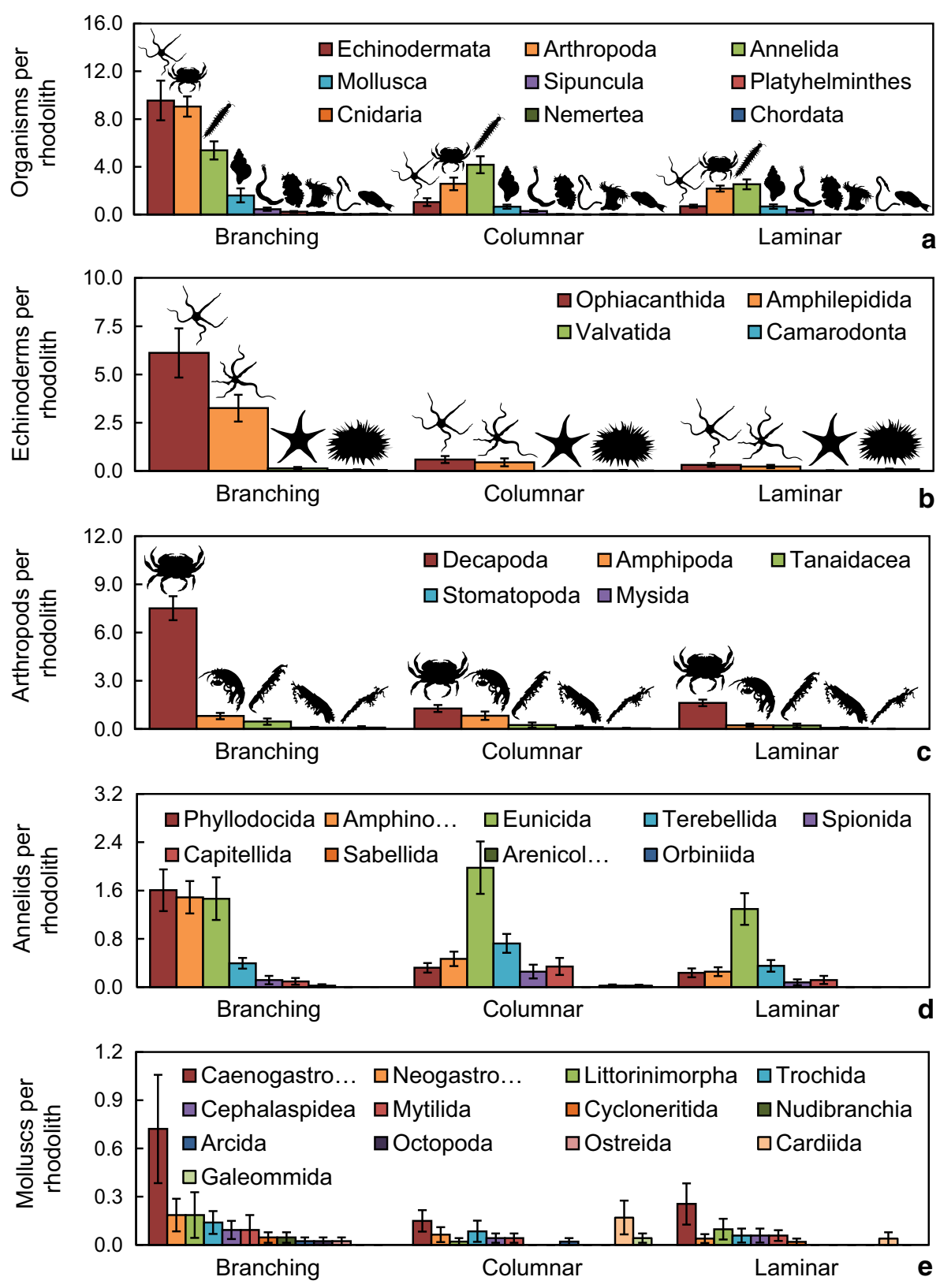
Additional tests show that Sipuncula associate with the Hilton site (GLM: $\left.\mathrm{X}^{2}=17.74, \mathrm{p}<0.0001\right)$.

\section{Discussion}

\section{Rhodolith distribution and characteristics}

\section{Rhodolith abundance and morphology and local wave activity}

Wave motion encourages rotation and regular growth of rhodoliths, which create larger, more abundant branching individuals (Bosselini and Ginsburg 1971; Marrack 1999) with rounder shapes (Scoffin et al. 1985). On Moorea, passes in the barrier reef expose opposing fringing reefs to long-period, high-power waves. As a result, pass-adjacent sites like Talari and Puutara support high abundances of large, branching, and spheroidal rhodoliths. Variable wave energy within these sites supports denser beds of larger, rounder, and more branching rhodoliths in deeper settings further from shore where breaking waves increase wave power.

In contrast, the protected Hilton site (Monismith et al. 2014) only experiences shorter-period waves generated in the lagoon, and thus contains fewer rhodoliths. The few rhodoliths present concentrate adjacent to shore where waves break and wave energy appears highest. The presence of rhodoliths at the Hilton site, in contrast to their absence at other protected sites, likely relates to its slightly higher wave energy, as expected given the large fetch for wave generation across the lagoon to the east (see Schopf 1980 for discussion of fetch). Differences in wave power between exposed and protected sites is likely more extreme than those documented in this study, as the waves we observed propagating through passes were derived from open ocean trade wind-generated waves. Substantially larger waves derived from distant polar storms episodically impact Moorea in the Northern Hemisphere winter (Hench et al. 2008; Edmunds et al. 2010). This phenomenon was not captured in our analysis, but is expected to deliver the largest waves to the exposed Talari and Puutara sites. Regular, high-quality imagery soon to be available will permit a more detailed seasonal assessment of local wave climates at lagoon study sites.

In Moorea, small tidal amplitude (Luther and Wunsch 1975) limits wave influence to a shallow depth band on the fringing reef. In other tropical fringing reefs, rhodolith presence likely also depends on other wave-related factors, including tidal amplitude and fetch across the lagoon. While passes in the barrier reef appear critical to the generation of large rhodolith aggregations in Moorea, they may not be the primary factor controlling rhodolith distribution on fringing reefs with different geomorphology, tides, or winds.

\section{Additional considerations}

Both ellipsoidal (Bosence 1976, 1983; Basso et al. 2009) and branching rhodoliths (Marrack 1999; Scoffin et al. 1985) roll more easily than other morphologies, and thus should occur at sites with lower wave energy. Consistent with this, we find ellipsoidal rhodoliths most frequently at our lowest wave energy site. However, we find branching rhodoliths at our higher wave energy sites, contrasting with other studies placing them more intermediately on their wave activity spectrums (Piller and Rasser 1996; Caragnano et al. 2016). These discrepancies suggest that existing studies have examined different suites of wave energy in different local contexts, and that rhodolith properties may have intermediate optima relative to wave energy. Below such an optimum, movement is insufficient to form a particular rhodolith type (Foster 2002), while above it transport out of the environment or breakage will eliminate that rhodolith type (Melbourne et al. 2020). Similarly, sufficient energy may be needed to clear rhodoliths of sediment, while greater movement may transport rhodoliths into environments where they are subject to burial (Jeong et al. 2020). As such, wave energy optima may reconcile the alternating attribution of rhodolith presence to both higher (e.g., Marrack 1999; Agnesi et al. 2020) and lower wave energy settings (e.g., Bosence 1976; Piller and Rasser 1996).

We are confident in the relative interpretation of wave climate employed in our analyses, but more detailed quantification of wave energy will require additional repeated measures. Given the small scale of the waves we analyzed, high resolution images were needed to resolve wavelength. However, only a limited number of images of sufficient quality were available to us. Larger waves pertinent to open ocean wave climate are easier to reconstruct (e.g., SAR: Jackson and Apel 2004); thus, studies at larger scales in deeper water settings (Italy: Agnesi et al. 2020; Ireland: Joshi and Farrell 2020) provide more quantitative reconstructions of rhodolith environment.

Although wave exposure strongly influences rhodolith morphology (Steller et al. 1993), specific algal taxa are also associated with particular rhodolith morphotypes (Bosence 1983; Basso et al. 2009). In Tahiti, Hydrolithon reinboldii is the dominant species in rhodolith beds, with Sporolithon ptychoides, Mesophyllum funafutiense, Melyvonnea erubescens, Porolithon onkodes, Neogoniolithon brassicaflorida, Lithophyllum kotschyanum, and H. rupestre also contributing to rhodolith formation (Nelson et al. 2017). However, we did not identify rhodolith-forming species in our study, and the species relevant to our sites in Moorea 
are yet unknown. Clearly, further research on the physical and biological controls of rhodolith morphology are merited.

\section{Cryptofaunal abundance and diversity}

\section{Cryptofaunal communities and local wave activity}

Wave activity indirectly influences cryptofaunal communities by controlling rhodolith abundance and morphology. Rhodolith abundance, size, and branching morphotype associate with wave exposure. Large and branching rhodoliths contain the most cryptofauna, presumably as a consequence of their higher internal complexity (Berlandi et al. 2012; Belanger 2020; Mendez Trejo et al. 2020). Thus, on fringing reefs, wave-exposed areas with higher abundances of large, branching rhodoliths contain more abundant and diverse cryptofauna. However, aspects of wave energy other than those affecting the rhodolith complexity may influence community composition (Peyrot-Clausade 1980; Blamey and Branch 2009) through enhanced recruitment (Reidenbach et al. 2009) or growth (McQuaid and Lindsay 2007). These aspects may also contribute to the observed patterns of abundance and diversity, and thus require further study.

Another relevant aspect of wave energy is physical disturbance. We expected cryptofaunal abundance and diversity to increase in beds due to their larger available habitat area (see MacArthur and Wilson 1963). However, we find that being within a rhodolith bed has no effect on the abundance and diversity within individual rhodoliths. Disturbance in wave-swept beds may be strong enough to counteract benefits from increased habitat area (see Sousa 1979 and Hinojosa-Arango et al. 2013 for discussion of intermediate disturbance). Alternatively, disturbance could affect taxa with specific modes of life (Hinojosa-Arango et al. 2009). Burrowing and filter feeding forms like sipunculans, terebellids, spinoids, and capitellids negatively associate with beds. Rhodoliths within beds may move more frequently than isolated rhodoliths; this higher disturbance in beds could hinder sessile filter feeding or detritivorous forms, as could the greater association of decapod predators with branching rhodoliths typically found in beds. Further research on the physical and ecological controls of rhodolith cryptofaunal diversity are merited.

\section{Cryptofaunal communities and structural complexity}

On Moorean fringing reefs, morphotype is the primary factor shaping rhodolith cryptofaunal communities. Active, rigid-bodied animals associate with internally spacious branching rhodoliths, while flexible taxa that can traverse restricted spaces and boring taxa that can generate habitat space do not associate with a particular morphotype. The relationship between active taxa and branching rhodoliths parallels recent observations from New Zealand (Mendez Trejo et al. 2020). However, literature discussing how invertebrates utilize interstitial space is limited, and focuses primarily on body size (e.g., Anderson and Meadows 1978; Warwick 1984; Pipan and Culver 2017) or freshwater systems (e.g., Gayraud and Philippe 2001; Lamouroux et al. 2004; Tomanova and Usseglio-Polatera 2007). The relationship between boring ability and existing space is similarly understudied (but see Hutchings 1981; Moran and Reaka 1988).

Branching rhodoliths provide complexity at limited scales, with spaces generally not exceeding a few centimeters. This is significant for organisms that mature to larger sizes, as they eventually outgrow rhodolith void spaces. For example, brittle stars occupy different habitats as they grow (Hendler and Littman 1986). This may explain observations of differing ophiuroid abundances in rhodoliths sampled at the same site over different years (Steller et al. 2003; Hinojosa-Arango and Riosmena-Rodriguez 2004). Observations of interannual variation in other taxa may relate to similar processes (McConnico et al. 2017). Pulses of recruitment may pass through rhodolith beds that accommodate organisms only at appropriate ontogenetic sizes. Subsequently, larger individuals might inhabit adjacent reef habitats with larger void spaces. Thus, rhodolith beds likely facilitate aspects of recruitment and maturation, particularly in relation to adjacent reef habitats (see Oterro Ferrer et al. 2018).

Rhodoliths may contribute to further explorations of porosity, connectivity, and diversity. The relationship between structural complexity and diversity has been extensively studied in coral reef fish (e.g., Roberts and Ormond 1987; Komyakova et al. 2013; Darling et al. 2017), but could be further developed in other contexts, particularly interstitial settings. Rhodoliths provide repeated natural sampling units with variable internal space that can be used to examine interplays between settlement, feeding, and water flow in these environments. This would permit further interrogation of biodiverse but understudied interstitial reef communities. Rhodoliths could also be compared to other complex substrates like coral rubble (e.g., Enochs et al. 2011) or Autonomous Reef Monitoring Structures (ARMS) (e.g., Baronio and Bucher 2008; Carvalho et al. 2019) to explore variable complexity at larger scales.

\section{Tropical evenness}

In contrast to studies in higher-latitude regions, we find a more even distribution of phyla, with Arthropoda, Annelida, Echinodermata, and Mollusca constituting 33, 30, 26, 
and $7 \%$ of total individuals, respectively. Single phyla dominate mid- to high-latitude rhodoliths (Alaska: Konar et al. 2006; New Zealand: Harvey and Bird 2008; South Australia: Nelson et al. 2012; California: Robinson 2015), while subtropical observations are intermediate in evenness (Mexico: Steller et al. 2003). This may reflect general latitudinal trends in diversity, which can be influenced by structural complexity (Bracewell et al. 2018). Further examination of rhodolith cryptofauna may support these trends, but comparison between studies is limited by differences in environmental context and sampling methodology. Thus, standardization of approaches would substantially benefit comparative studies.

\section{Summary}

We provide one of the few studies of rhodoliths on tropical fringing reefs, and the first such study to consider the morphology and cryptofauna of rhodoliths in detail. In Moorea, a wave-dominated reef system, the abundance of morphology of fringing reef rhodoliths are associated with sites exposed to ocean waves penetrating the lagoon. At these sites, locations where larger waves impact the outer edge of the fringing reef support dense aggregations of larger, rounder, and more branching rhodoliths. Branching morphotype and large rhodolith size strongly associate with cryptofaunal abundance and diversity. In particular, hard-bodied and motile, non-burrowing organisms are associated with the complex architecture provided by branching forms. Wave energy appears to indirectly operate on rhodolith cryptofauna through higher proportions of large, branching rhodoliths. Thus, wave energy appears to be an important attribute constraining the distribution of rhodoliths and associated fringing reef cryptofauna.

Supplementary Information The online version contains supplementary material available at https://doi.org/10.1007/s00338021-02214-7.

\begin{abstract}
Acknowledgements We thank Hinano Murphy for providing appropriate Tahitian place names for our study sites, the entire Gump Station staff for supporting our research, and Libe Washburne for discussions of waves and wave quantification. We greatly appreciate the effort that has gone into sustaining the UCLA Marine Biology Quarter over the years by staff, faculty, and alumni of the program. We also thank Terri for providing us comfort and coffee after a boating mishap.
\end{abstract}

Funding We received funding from the UCLA Ecology and Evolutionary Biology department. Benjamin A. Hà received funding from NSF GRFP Grant \#1650604.

\section{Declarations}

Conflict of interest On behalf of all authors, the corresponding author states that there is no conflict of interest.
Open Access This article is licensed under a Creative Commons Attribution 4.0 International License, which permits use, sharing, adaptation, distribution and reproduction in any medium or format, as long as you give appropriate credit to the original author(s) and the source, provide a link to the Creative Commons licence, and indicate if changes were made. The images or other third party material in this article are included in the article's Creative Commons licence, unless indicated otherwise in a credit line to the material. If material is not included in the article's Creative Commons licence and your intended use is not permitted by statutory regulation or exceeds the permitted use, you will need to obtain permission directly from the copyright holder. To view a copy of this licence, visit http://creativecommons. org/licenses/by/4.0/.

\section{References}

Agnesi S, Annunziatelis A, Inghilesi R, Mo G, Orasi A (2020) The contribution of wind-wave energy at sea bottom to the modeling of rhodolith beds distribution in an off-shore continental shelf. Mediterr Mar Sci 21:433-441

Amado-Filho GM, Moura RL, Bastos AC, Salgado LT, Sumida PY, Guth AZ, Francini-Filho RB, Pereira-Filho GH, Abrantes DP, Brasileiro PS, Bahia RG, Leal RN, Kaufman L, Kleypas JA, Farina M, Thompson FL (2012) Rhodolith beds are major $\mathrm{CaCO}_{3}$ bio-factories in the tropical South West Atlantic. PloS one $7: 35171$

Anderson JG, Meadows PS (1978) Microenvironments in marine sediments. Proc R Soc Edinb 76B:1-16

Baronio MA, Bucher DJ (2008) Artificial crevice habitats to assess the biodiversity of vagile macro-cryptofauna of subtidal rocky reefs. Mar Freshw Res 59:661-670

Basso D, Nalin R, Nelson CS (2009) Shallow-water Sporolithon rhodoliths from North Island (New Zealand). Palaios 24:92-103

Belanger D (2020) Growth controls of rhodoliths (Lithoamnion glaciale) and relationships between structural complexity and macrofaunal diversity in subarctic rhodolith beds. Ph.D. thesis, Memorial University of Newfoundland.

Berlandi RM, Figueiredo MAO, Paiva PC (2012) Rhodolith morphology and the diversity of polychaetes off the southeastern Brazilian Coast. J Coast Res 28:280-287

Blake C, Maggs CA (2003) Comparative growth rates and internal banding periodicity of maerl species (Corallinales, Rhodophyta) from northern Europe. Phycologia 42:606-612

Blamey LK, Branch GM (2009) Habitat diversity relative to wave action on rocky shores: implications for the selection of marine protected areas. Aquat Conserv 19:645-657

Bosence DWJ (1976) Ecological studies on two unattached coralline algae from Western Ireland. Palaeontology 19:365-395

Bosence DWJ (1983) Description and Classification of Rhodoliths (Rhodoids, Rhodolites). In: Peryt TM (ed) Coated grains, 1st edn. Springer Science and Business Media, Berlin, pp 219-266

Bosselini A, Ginsburg RN (1971) Form and internal structure of recent algal nodules (Rhodolites) from Bermuda. J Geol 79:669-682

Bracewell SA, Clark GF, Johnston EL (2018) Habitat complexity effects on diversity and abundance differ with latitude: an experimental study over 20 degrees. Ecology 99:1964-1974

Brock RE, Smith SV (1983) Response of coral reef cryptofaunal communities to food and space. Coral Reefs 1:179-183

Caragnano A, Basso D, Rodondi G (2016) Growth rates and ecology of coralline rhodoliths from the Ras Ghamila back reef lagoon, Red Sea. Mar Ecol 37:713-726 
Carvalho S, Eva A, Villalobos R, Kattan Y, Berumen M, Pearman JK (2019) Beyond the visual: using metabarcoding to characterize the hidden reef cryptobiome. Proc R Soc B 286:20182697

Clark RN (2000) The chiton fauna of the Gulf of California rhodolith beds (with the descriptions of four new species). Nemouria: Occasional Papers of the Delaware Museum of Natural History 43: $1-18$

Darling ES, Graham NAJ, Januchowski-Hartley FA, Nash KL, Pratchett MS, Wilson SK (2017) Relationships between structural complexity, coral traits, and reef fish assemblages. Coral Reefs 36:561-575

Darrenougue N, De Deckker P, Payri C, Eggins S, Fallon S (2013) Growth and chronology of the rhodolith-forming, coralline red alga Sporolithon durum. Mar Ecol Prog Ser 474:105-119

Enochs IC (2012) Motile cryptofauna associated with live and dead coral substrates: implications for coral mortality and framework erosion. Mar Bol 159:709-722

Enochs IC, Toth LT, Brandtneris VW, Afflerbach JC, Manzello DP (2011) Environmental determinants of motile cryptofauna on an easten pacific coral reef. Mar Ecol Prog Ser 438:105-118

Fauchald K (1977) The Polychaete worms: definitions and keys to the orders, families, and genera natural history Museum of Los Angeles County. Sci Ser 28:1-188

Figueiredo MAO, Santos de Menezes K, Costa Paiva EM, Paiva PC, Ventura CRR (2007) Experimental evaluation of rhodoliths as living substrata for infauna at the Abrolhos Bank Brazil. Cienc Mar 33: 427-440

Foster MS (2002) Rhodoliths: between rocks and soft places. J Phycol 37:659-667

Foster MS, Amado Filho GM, Kamenos NA, Riosmena-Rodríguez R, Steller DL (2013) Rhodoliths and rhodolith beds. Smithson Contrib Mar Sci 39:143-155

Frantz BR, Kashgarian M, Coale KH, Foster MS (2000) Growth rate and potential climate record from a rhodolith using ${ }^{14} \mathrm{C}$ accelerator mass spectrometry. Limnol Oceanogr 45:1773-1777

Gayraud S, Philippe M (2001) Does subsurface interstitial space influence general features and morphological traits of the benthic macroinvertebrate community in streams? Fundam Appl Limnol 151:667-686

Graham DJ, Midgley NG (2000) Graphical representation of particle shape using triangular diagrams: an Excel spreadsheet method. Earth Surf Process Landf 25:1473-1477

Harvey AS, Bird FL (2008) Community structure of a rhodolith bed from cold-temperate waters (southern Australia). Aust J Bot $56: 437-450$

Hench JL, Leichter JJ, Monismith SG (2008) Episodic circulation and exchange in a wave-driven reef and lagoon system. Limnol Oceanogr 53:2681-2694

Hendler G, Littman BS (1986) The ploys of sex: relationships among the mode of reproduction, body size and habitats of coral-reef brittle stars. Coral Reefs 5:31-42

Hinojosa-Arango G, Riosmena-Rodríguez R (2004) Influence of rhodolith-forming species and growth-form on associated fauna of rhodolith beds in the central-west Gulf of California, México. Mar Ecol 25:109-127

Hinojosa-Arango G, Maggs CA, Johnson MP (2009) Like a rolling stone: the mobility of maerl (Corallinaceae) and the neutrality of the associated assemblages. Ecology 90:517-528

Hinojosa-Arango G, Maggs CA, Johnson MP, Riosmena-Rodríguez R (2013) When rhodoliths do not roll: invertebrate community responses to environmental stability and natural disturbance. In: Riosmena-Rodríguez R (ed) Invertebrates: classification, evolution, and biodiversity. Nova Science Publishers Inc, New York, pp 131-151
Hutchings PA (1981) Polychaete recruitment onto dead coral substrates at Lizard Island, Great Barrier Reef, Australia. Bull Mar Sci 31:410-423

Hutchings PA, Weate PD (1977) Distribution and abundance of cryptofauna from Lizard Island, Great Barrier Reef. Mar Res Indones 17:99-112

Jackson CR and Apel JR (eds) (2004) Synthetic aperture radar marine user's manual. National Environmental, Satellite, Data, and Information Service.

Jeong JB, Kim SY, Seo YK, Kim J-K, Shin J, W KS, (2020) Influence of submarine topography and associated sedimentary processes on the distribution of live and dead rhodoliths near Udo Island, Korea. Geo-Mar Lett 40:35-51

Joshi S, Farrell E (2020) Physical oceanographic drivers of geomorphology of rhodolith/maerl beds in Galway Bay, Island. In: Harris PT, Baker E (eds) Seafloor geomorphology as benthic habitats: GeoHab atlas of seafloor geomorphic features and benthic habitats, 2nd edn. Elsevier Inc., Amsterdam, pp 231-242

Keegan BF (1974) The macrofauna of maerl substrates of the West coast of Ireland. Cah Biol Mar 15: 513-530

Knowlton N, Brainard RE, Fisher R, Moews M, Plaisance L, Caley MJ (2010) Coral reef biodiversity. In: McIntyre AD (ed) Life in the world's oceans diversity, distribution, and abundance. Wiley, Hoboken

Komyakova V, Munday PL, Jones GP (2013) Relative importance of coral cover, habitat complexity and diversity in determining the structure of reef fish communities. PLoS One 8:83178

Konar B, Riosmena-Rodríguez R, Iken K (2006) Rhodolith bed: a newly discovered habitat in the North Pacific Ocean. Bot Mar 49:355-359

Lamouroux N, Dolédec S, Gayraud S (2004) Biological traits of stream macroinvertebrate communities: effects of microhabitat, reach, and basin filters. J North Am Benthol Soc 23:449-466

Luther DS, Wunsch C (1975) Tidal charts of the central Pacific Ocean. J Phys Oceanogr 5:222-230

MacArthur RH, Wilson EO (1963) An equilibrium theory of insular zoogeography. Evolution 17:373-387

Marrack EC (1999) The relationship between water motion and living rhodolith beds in Southwestern Gulf of California, Mexico. Palaios 14:159-171

McConnico LA, Hernández Carmona G, Martínez Morales JS, Riosmena-Rodríguez R (2017) Temporal variation in seaweed and invertebrate assemblages in shallow rhodolith beds of Baja California Sur, México. Aquat Bot 139:37-47

McQuaid CD, Lindsay TL (2007) Wave exposure effects on population structure and recruitment in the mussel Perna perna suggest regulation primarily through availability of recruits and food, not space. Mar Biol 151:2123-2131

Melbourne LA, Denny MW, Harniman RL, Rayfield EJ, Schmidt DN (2020) The importance of wave exposure on the structural integrity of rhodoliths. J Exp Mar Biol Ecol 503:109-119

Méndez Trejo MC, Neill KF, Twist BA, Nelson WA (2020) Cryptofauna associated with rhodoliths: diversity is speciesspecific and influenced by habitat. Mar Ecol 42:12647

Meyer, C (2017) Moorea Biocode Project. University of California: Berkeley. http://biocode.berkeley.edu

Monismith SG (2014) Flow through a rough, shallow reef. Coral Reefs 33:99-104

Moran DP, Reaka ML (1988) Bioerosion and availability of shelter for benthic reef organisms. Mar Ecol Prog Ser 44:240-263

Nebelsick JH, Bassi D, Rasser MW (2011) Microtaphofacies: exploring the potential for taphonomic analysis in carbonates. In: Allison PA, Bottjer DJ (eds) Taphonomy: process and bias through time, 2nd edn. Springer, Dordrecht, pp 587-621 
Nelson WA (2009) Calcified macroalgae-critical to coastal ecosystems and vulnerable to change: a review. Mar Freshw Res 60:787-801

Nelson W, Neill K (2017) South Pacific. In: Riosmena-Rodríguez R, Nelson W, Aguirre J (eds) Rhodolith/Maërl beds: a global perspective. Springer International Publishing Switzerland, Cham, pp 349-359

Nelson W, Neill K, Farr T, Barr N, D'Archino R, Miller S, Stewart R (2012) Rhodolith beds in northern New Zealand: characterization of associated biodiversity and vulnerability to environmental stressors. New Zealand Aq Environ Biodiv Rep 99:106

Nitsch F, Nebelsick J, Bassi D (2015) Constructional and destructional patterns-void classification of rhodoliths from Giglio Island, Italy. Palaios 30:680-691

Oterro Ferrer F, Mannarà E, Cosme De Esteban M, Falace A, Montiel-Nelson JA, Espino F, Haroun R, Tuya F (2018) Heterogeneity rather than size determines faunal colonization of discrete habitat units: a case study with rhodolith-associated macrofauna. VI International Rhodolith Workshop. Station Biologique de Roscoff, Brittany.

Peyrout-Clausade M (1980) Motile cryptofauna of Tuléar reef flats. Mar Biol 59:43-47

Piller WE, Rasser M (1996) Rhodolith formation by reef erosion in the Red Sea. Egypt Coral Reefs 15:191-198

Pipan T, Culver DC (2017) The unity and diversity of the subterranean realm with respect to invertebrate body size. J Caves Karst Stud 79:1-9

Pollock JB (1928) Fringing and fossil coral reefs of Oahu. Bernice P. Bishop Museum Bulletin 55: 3-56.

Reidenbach MA, Koseff JR, Koehl MAR (2009) Hydrodynamic forces on larvae affect their settlement on coral reefs in turbulent, wave-driven flow. Limnol Oceanogr 54:318-330

Roberts CM, Ormond RFG (1987) Habitat complexity and coral reef diversity and abundance on Red Sea fringing reefs. Mar Ecol Prog Ser 41:1-8

Robinson KM (2015) Motile cryptofaunal invertebrate assemblages in Catalina Island's rhodolith beds in relation to physical structure and live rhodoliths. Master's thesis, CSU: Monterey Bay.

Salvat B, Rives C (1991) Coquillages de Polynésie. Delachaux et Niestlé, Neuchâtel

Schopf TJM (1980) Paleoceanography. Harvard University Press, Cambridge
Scoffin TP, Stoddart DR, Tudhope AW, Woodroffe C (1985) Rhodoliths and coralliths of Muri Lagoon, Rarotonga, Cook Islands. Coral Reefs 4:71-80

Sneed ED, Folk RL (1958) Pebbles in the lower Colorado River, Texas: a study in particle morphogenesis. J Geol 66:114-150

Sousa WP (1979) Disturbance in marine intertidal boulder fields: the nonequilibrium maintenance of species diversity. Ecology 60:1225-1239

Spieler RE, Gilliam DS, Sherman RL (2001) Artificial substrate and coral reef restoration: what do we need to know to know what we need. Bull Mar Sci 2:1013-1030

Steller DL (1993) Ecological studies of rhodoliths in Bahía Concepcíon, Baja California Sur, México. Master's thesis, San Jose State University.

Steller DL, Foster MS (1995) Environmental factors influencing distribution and morphology of rhodoliths in Bahía Concepcíon, B.C.S. México J Exp Mar Biol Ecol 194:201-212

Steller DL, Cáceres-Martínez C (2009) Coralline algal rhodoliths enhance larval settlement and early growth of the Pacific calico scallop Argopecten ventricosus. Mar Ecol Prog Ser 396:49-60

Steller DL, Riosmena-Rodríguez R, Foster MS, Roberts CA (2003) Rhodolith bed diversity in the Gulf of California: the importance of rhodolith structure and consequences of disturbance. Aquat Conserv 13(S1):S5-S20

Sverdrup HU, Johnson MW, Fleming RH (1942) The oceans, their physics, chemistry, and general biology. Prentice-Hall, New York

Teichert S (2014) Hollow rhodoliths increase Svalbard's shelf biodiversity. Sci Rep 4:6972

Tomanova S, Usseglio-Polatera P (2007) Patterns of benthic community traits in neotropical streams: relationship to mesoscale spatial variability. Fundam Appl Limnol 170:243-255

Warwick RM (1984) Species size distributions in marine benthic communities. Oecologia 61:32-41

Weber-van Bosse A, Foslie M (1904) The Corallinaceae of the Siboga-expedition. Brill Publishers and Printers, Leyden, E.J

WoRMS Editorial Board (2020) World register of marine species. Flanders Marine Institute. https://www.marinespecies.org

Publisher's Note Springer Nature remains neutral with regard to jurisdictional claims in published maps and institutional affiliations. 